\title{
Finding of the Thermophilic Harpacticoid Species Elaphoidella bidens (Schmeil 1893) in the Vychegda River (Northern Dvina, White Sea Basin)
}

\author{
Elena B. Fefilova* \\ Institute of Biology of Komi Scientific Centre UB RAS \\ Syktyvkar, Russian Federation
}

Received 15.03.2019, received in revised form 18.07.2019, accepted 08.09.2019, published online 15.05.2020

\begin{abstract}
A harpacticoid copepod (Copepoda: Harpacticoida) species, Elaphoidella bidens, which was new for the North-East of European Russia, was found in the Vychegda River in July 2018. The species was identified in the area where heated wastewater is discharged from the wood-processing plant. The species was found in the extreme north of its range $\left(61^{\circ} 48^{\prime} \mathrm{N}\right)$. The present study compares the morphological, biological and ecological properties of this species with those of another native representative of the genus - E. gracilis. Comparison of morphology of the Vychegda E. bidens and individuals from tropical populations (New Zealand, Borneo, Vietnam) and populations of the temperate zone (Romania, Lake Glubokoe in Moscow region) showed that the structures of their antennae, body somites, swimming and rudimentary legs, and the caudal rami were similar in representatives of all populations. The fact that a thermophilic species was found for the first time in the northern region is indicative of potential changes in fauna diversity caused by thermal pollution or warming.
\end{abstract}

Keywords: thermophilic species, water ecosystems, Vychegda basin, anthropogenic effect, harpacticoid copepods, intraspecific morphological variation, ranges.

Citation: Fefilova E.B. Finding of the thermophilic harpacticoid species Elaphoidella bidens (Schmeil 1893) in the Vychegda River (Northern Dvina, White Sea basin). J. Sib. Fed. Univ. Biol., 2020, 13(4), 443-452. DOI: 10.17516/1997-1389-0319

(C) Siberian Federal University. All rights reserved

This work is licensed under a Creative Commons Attribution-NonCommercial 4.0 International License (CC BY-NC 4.0).

* Corresponding author E-mail address: fefilova@ib.komisc.ru

ORCID: 0000-0001-9329-3030 


\title{
Находка теплолюбивого вида гарпактикоиды Elaphoidella bidens (Schmeil 1893) \\ в р. Вычегда (бассейн Северной Двины Белого моря)
}

\author{
Е.Б. Фефилова \\ Институт биологии Коми научного центтра УрО РАН \\ Российская Федераџия, Сыктывкар
}

\begin{abstract}
Аннотация. В июле 2018 г. в р. Вычегда в районе сброса подогреваемых сточных вод очистных сооружений лесоперерабатывающего предприятия был найден новый для северо-востока европейской части России вид гарпактикоиды (Copepoda: Harpacticoida) - Elaphoidella bidens.

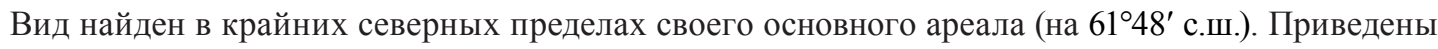
его морфологические, биологические и экологические особенности в сравнении с другим, аборигенным, представителем рода -E. gracilis. Сравнение морфологии вычегодской E. bidens и особей из популяций тропических областей (Новая Зеландия, Борнео, Вьетнам) и умеренной зоны (Румыния, оз. Глубокое в Московской области) показало, что строение антенн, сегментов тела, плавательных и рудиментарных конечностей и каудальных ветвей оказались общими для представителей всех популяций. Находка термофильного вида впервые в северном регионе показательна с точки зрения фиксации потенциальных изменений разнообразия фауны при тепловом загрязнении или потеплении.
\end{abstract}

Ключевыеслова:термофильный вид, водныеэкосистемы, Вычегодский бассейн, антропогенное влияние, гарпактикоиды, внутривидовая морфологическая изменчивость, ареалы.

Цитирование: Фефилова, Е.Б. Находка теплолюбивого вида гарпактикоиды Elaphoidella bidens (Schmeil 1893) в р. Вычегда (бассейн Северной Двины Белого моря) / Е.Б. Фефилова // Журн. Сиб. федер. ун-та. Биология, 2020. 13(4). C. 443-452. DOI: 10.17516/1997-1389-0319

\section{Введение}

Река Вычегда - один из крупнейших водотоков на северо-востоке европейской части России. Водосбором ее левобережных притоков собственно ограничена территория этого региона, на севере простирающегося вплоть до побережья Баренцева моря и включающего кроме Вычегодского бассейна полностью Печорский бассейн и частично бассейн р. Мезень, зоны тундр, северной, средней и южной тайги. Большая часть Вычегодского бассейна лежит в северотаежной зоне (рис. 1). В результате сравнительно недавней ревизии фа- уны веслоногих раков (Copepoda) внутренних вод северо-востока европейской части России (Фефилова, 2015) в список таксонов гарпактикоид (Harpacticoida) для региона было внесено 33 вида и подвида. Из них для бассейна p. Вычегда указано 14 видов и подвидов, относящихся к 10 родам. Из рода Elaphoidella в обоих этих списках приведен лишь один таксон - Elaphoidella gracilis (G.O. Sars 1862). По географии ареала это наиболее северный представитель крупного рода, насчитывающего более двухсот видов (World of Copepods). В Европе эта гарпактикоида встречается по- 


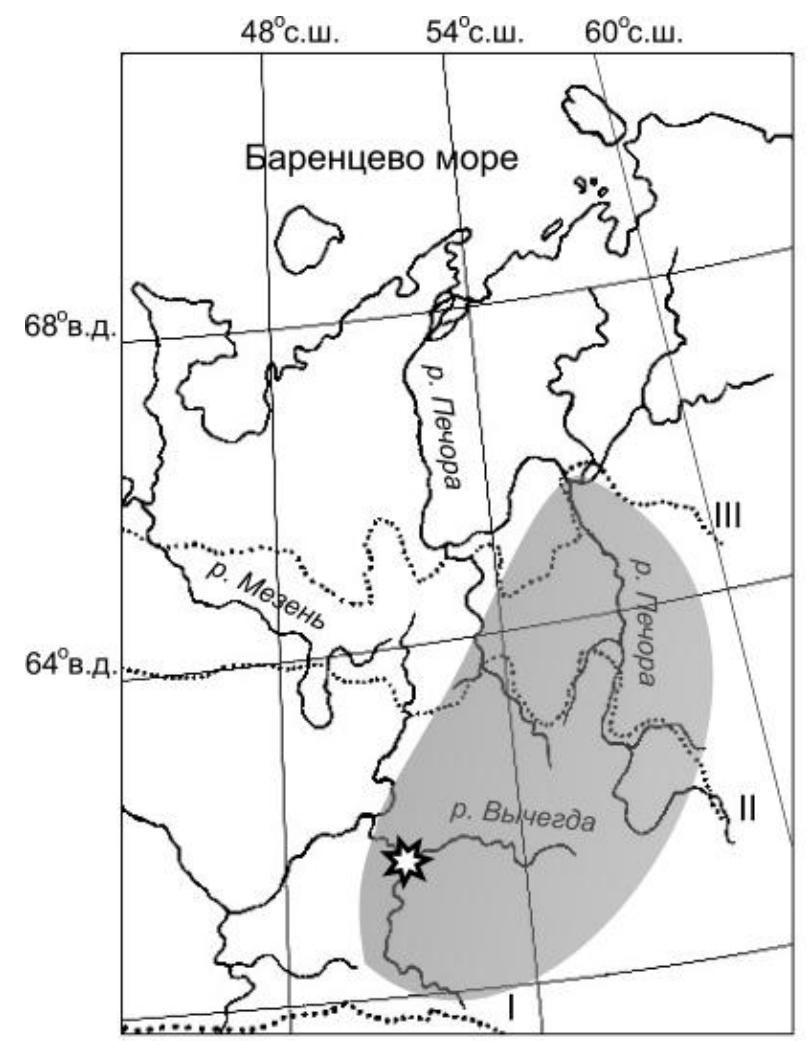

Рис. 1. Карта распространения Elaphoidella gracilis (серая область) по (Фефилова, 2015) и место нахождения E. bidens (р. Вычегда) (звездочка) на северо-востоке европейской части России. I, II, III границы зон растительности: I - граница южной и средней тайги; II - граница средней и северной тайги; III - граница северной и крайне северной тайги

Fig. 1. The map of distribution of Elaphoidella gracilis (gray area) according to (Fefilova, 2015) and point of finding of E. bidens (the Vychegda River) (asterisk) in the North-East of European Russia. I, II, III - boundaries of the vegetation zones: I - the boundary between the southern and middle taiga, II - the boundary between the middle and northern taiga, III - the boundary between the northern and extreme northern taiga

всеместно, кроме арктической области, населяет пресные водоемы разного типа (Боруцкий, 1952; Damian-Georgescu, 1970; Фефилова, 2015), была обнаружена в полостях стеблей гниющих водных растений (Green, 1959) и почвах широколиственных лесов (Fiers, Ghenne, 2000). Остальные Elaphoidella распространены всесветно и наибольшего разнообразия достигают в поверхностных, пещерных и грунтовых водах тропиков и субтропиков (Fefilova, Alekseev, 2018). Нами впервые зарегистрирован новый для северо-востока европейской части России и бассейна р. Вычегда вид Elaphoidella. Целью данной работы было описание этой находки и обсуждение возможных причин появления вида за границами его известного ареала.

\section{Материалы и методы}

Материалом для исследований послужили ракообразные из проб бентоса, переданные автору М.А. Батуриной (Институт биологии Коми научного центра УрО РАН). Пробы (15 штук) были отобраны из русла р. Вычегда 23 июля 2018 г. на участке между Эжвинским районом г. Сыктывкара и местечком Сотче- 
мью (49,3 км) (614ㅇ' с.ш., 5043' в.д.) (рис. 1). В этом районе в русло реки поступают подогретые сточные воды очистных сооружений лесоперерабатывающего предприятия АО “Монди СЛПК” (непосредственно под сливом было собрано 3 пробы зообентоса). Параллельно с отбором гидробиологических проб были собраны гидрохимические пробы (7 штук, две из них - под сливной трубой). Температура воды в реке при отборе проб составляла $25,1-25,5{ }^{\circ} \mathrm{C}, \mathrm{pH}: 6,38$, цветность воды 350-370 град., БПК $1,19-1,43$ мг О О $_{2}$ дм $^{3}$, $\mathrm{N}_{\text {общ. }}<0,5$ мг/дм³, $\mathrm{P}_{\text {общ. }}$ 0,053-0,061 мг/дм³. Эти и другие учтенные показатели качества воды (концентрации солей, металлов) существенно не отличались на всем исследованном отрезке реки.

Пробы отбирали с помощью дночерпателя Петерсена с площадью захвата $1 / 40 \mathrm{~m}^{2}$. Концентрировали пробы, промывая их в полевых условиях через капроновое сито с размером ячеи 230 мкм. Затем пробы фиксировали раствором формальдегида с массовой долей 4 \%. Дальнейшую их обработку проводили в условиях лаборатории. Гарпактикоид просматривали под микроскопом Leica DM 4000 В. Рисунки выполняли с помощью рисовального устройства при увеличении в 1000 раз.

Анализ химического состава воды р. Вычегда был выполнен в экоаналитической лаборатории Института биологии Коми научного центра Уральского отделения Российской академии наук (Аттестат аккредитации № РОСС RU.0001.511257 от 26 февраля 2014 г.).

\section{Результаты и обсуждение}

Единственная самка гарпактикоиды Elaphoidella bidens (Schmeil 1893) была найдена нами в пробе бентоса из русла р. Вычегда, отобранной непосредственно под сливом сточной воды из очистных сооружений лесоперерабатывающего предприятия АО “Монди СЛПК”. Строение найденной особи в основном соответствовало описанию вида в определителях (Боруцкий, 1952; Wells, 2007). Главными диагностическими признаками E. bidens являются грубо зазубренные задние края сегментов тела, наличие порядка десяти крупных довольно тупых зубчиков на анальной пластинке и характерное строение каудальных ветвей: на их спинной стороне имеется треугольный гребень (рис. 2, 3). По совокупности этих признаков E. bidens хорошо отличается от других Elaphoidella и E. gracilis, распространенной в Вычегодском бассейне. В то же время для E. bidens характерна большая морфологическая изменчивость, касающаяся тонкого вооружения сегментов тела, эндоподитов плавательных конечностей, строения рудиментарной конечности (Р5), тонкого вооружения каудальных ветвей, а также придатков антенн и мандибул (Боруцкий, 1952; Damian-Georgescu, 1970; Apostolov, 2007; Wells, 2007; Caramujo, Boavida, 2009; Fefilova, Alekseev, 2018). На основании различий по этим признакам ранее было описано шесть подвидов из разных частей света (World of Copepods), статус которых требует подтверждения, так как есть мнение (Apostolov, 2007), что их характеристики неустойчивы, а изменчивость вида можно объяснить различиями условий среды в местах обитания. Для пресноводных гарпактикоид такая изменчивость известна (Боруцкий, 1952; Фефилова, 2015), хотя ее также связывают с воздействием географических факторов: формированием морфологических и генетических особенностей у малоподвижных организмов в условиях относительной изолированности популяций (Kochanova et al., 2018; Kochanova, Gaviria, 2018).

E. bidens распространена чрезвычайно широко. Этот вид обычен в водоемах тропи- 


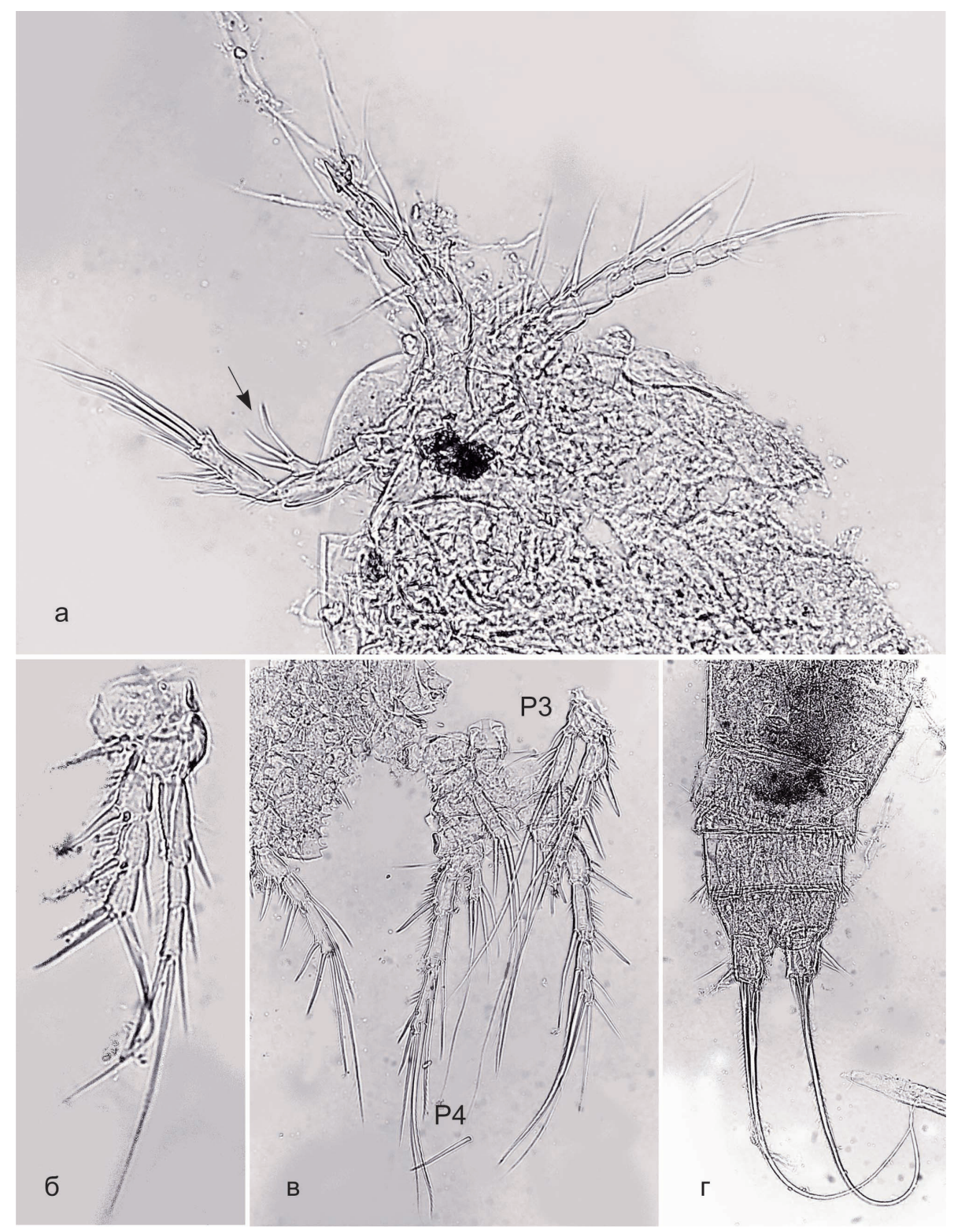

Рис. 2. Строение самки Elaphoidella bidens из р. Вычегда (фото), 23 июля 2018 г.: а - антеннулы, антенна с придатком (показан стрелкой); б - нога первой пары; в - ноги третьей (Р3) и четвертой пар (Р4); г абдомен и каудальные ветви

Fig. 2. Structure of a female of Elaphoidella bidens from the Vychegda River (photo), 23 July 2018: a - antenna with adnexa (shown by the arrow); 6 - first leg; в - third (P3) and fourth (P4) legs; $\Gamma$ - abdomen and caudal rami

ческих и субтропических областей Старого и Нового света: прудах, каналах, озерах, рисовых чеках и т.д. (Боруцкий, 1952; DamianGeorgescu, 1970; Lewis, 1972; Reid, 2001; Apostolov, 2007; Fefilova, Alekseev, 2018). В Европе его наиболее северные указания от- носятся к Ладожскому озеру (Sarkka, 1995), оз. Глубокому в Московской области (Фефилова, 2017), Рыбинскому водохранилищу (Гусаков, 2007). В США, например, вид (форма E. bidens coronata G.O. Sars 1904) распространен от Миннесоты до Луизианы (Reid, 


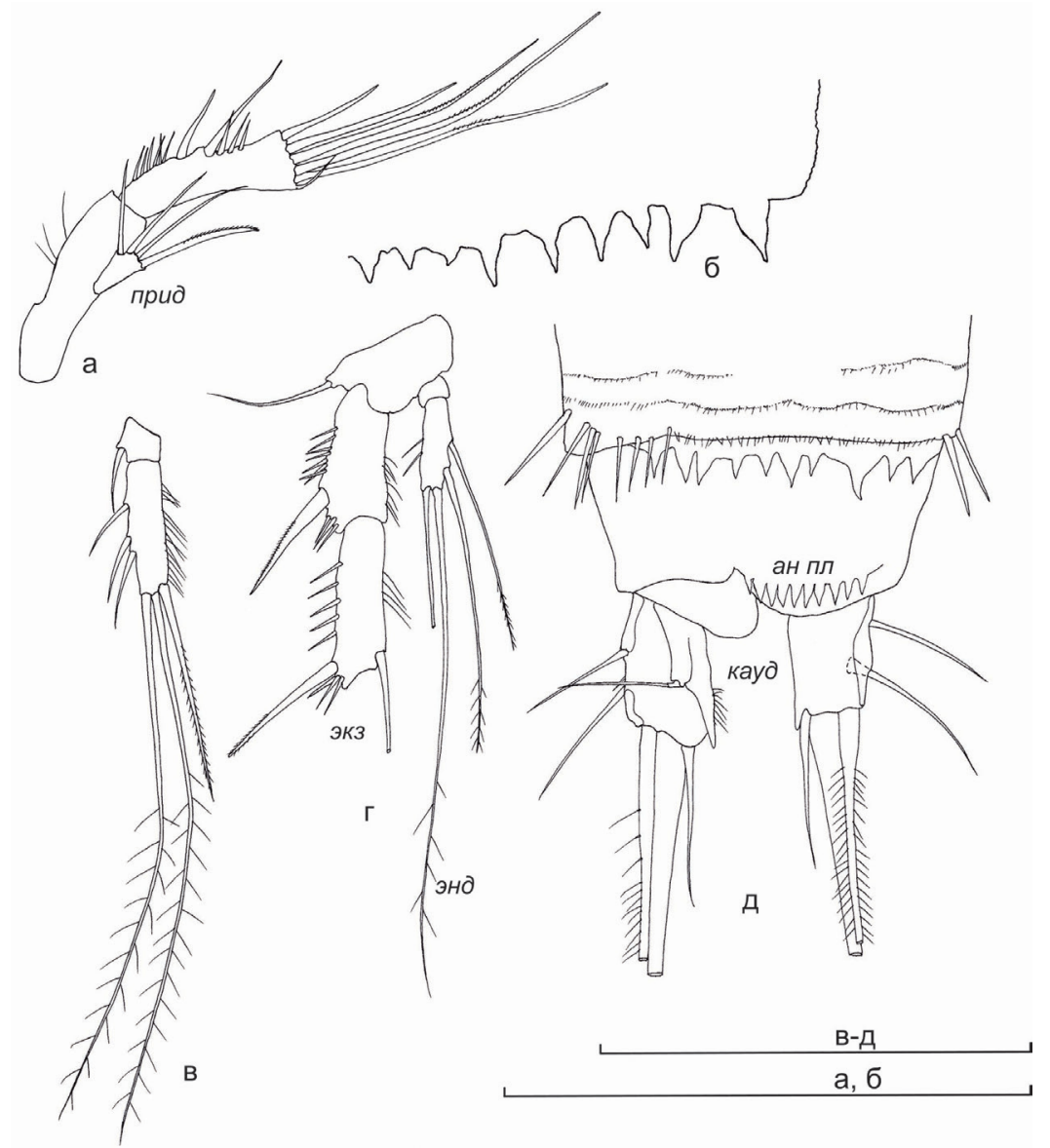

Рис. 3. Строение самки Elaphoidella bidens из р. Вычегда, 23 июля 2018 г.: а - антенна; б - задний край сегмента тела; в - эндоподит ноги третьей пары; г - нога четвертой пары (экзоподит - частично); д - анальный сегмент и каудальные ветви дорсально; прид - придаток антенны, экз - экзоподит, энд эндоподит, ан пл - анальная пластинка, кауд - каудальные ветви. Масштаб: 0,1 мм

Fig. 3. Structure of a female of Elaphoidella bidens from the Vychegda River, 23 July 2018: a - antenna; 6 - posterior margin of a body somite; в - endopod of third leg; $\Gamma$ - fourth leg (exopod - partly); д - anal somite and caudal rami dorsally; прид - appendage of antenna, экз - exopod, энд - endopod, ан пл - anal operculum, кауд - caudal rami. Scale: $0.1 \mathrm{~mm}$

Williamson, 2010), есть указания E. bidens для Канады (Neilson, Fuller, 2018). Однако по сравнению с E. gracilis E. bidens проявляет себя как более теплолюбивый. Так, в литорали Рыбинского водохранилища из гарпактикоид только E. bidens (наряду с Nitocrella hibernica Brady 1880) не пережила на постэмбриональных стадиях промерзание водоема, остальные представители отряда оказались после восстановления благоприятных условий вполне жизнеспособными (Гусаков, 2007). На Борнео
E. bidens нормально развивается в водоемах при температуре $30-31{ }^{\circ} \mathrm{C}$ (Alekseev et al., 2016; Fefilova, Alekseev, 2018), в Пуэрто-Рико выживает в термальных водах (Reid, 2001). Очевидно, что температурные преферендумы для этого вида сдвинуты относительно E. gracilis в сторону более высоких значений и E. bidens можно охарактеризовать по отношению к температуре как стенотермный термофильный таксон. Об этом свидетельствует также приуроченность этой гарпактикоиды в 
умеренной зоне к крупным глубоким водоемам (Ладожское озеро, Рыбинское водохранилище, оз. Глубокое), которые зимой в большей части своей акватории никогда не промерзают до дна. При таких температурных предпочтениях E. bidens находка этого вида в р. Вычегда вызывает интерес.

Климатические условия в пункте обнаружения нового вида достаточно суровые для развития термофильных форм: среднегодовая температура воздуха здесь составляет около $0{ }^{\circ} \mathrm{C}$, зимой водоемы устойчиво покрыты льдом (Голдина, Овчинникова, 1964). Однако известно, что эти таксоны могут присутствовать как азональный элемент в составе фаун подогреваемых и незамерзающих вод некоторых регионов, причем как в качестве реликтов, так и в качестве неоэндемиков (Тахтеев и др., 2010; Болотов и др., 2016).

Очевидно, что широкого распространения в регионе исследований E. bidens не получила, вселение вида произошло относительно недавно на небольшом участке русла реки и связано оно с подогреваемыми сточными водами очистных сооружений лесоперерабатывающего комплекса, основное влияние которых проявляется в зимний период, летом температура подогретых вод соответствует фоновым. Остается открытым вопрос о возможных источнике и способе проникновения вида в новое для него местообитание за пределами основного ареала. Наиболее вероятным кажется внесение рачка в реку с очищенными сточными водами, так как в резервуарах для их отстаивания выявлена своеобразная по составу беспозвоночных фауна, в которой тем не менее не найдены веслоногие раки (Кононова О.Н., Батурина М.А., устное сообщение). В то же время многие виды копепод, в частности гарпактикоид, встречаются по всему миру в водопроводных системах, фильтрах, фонтанах, аквариумах и тому подобных био- топах, созданных человеком, хотя E. bidens для них не указана (Reid, 2001).

Другим источником нового вида в p. Вычегда может быть природный водоем, расположенный в пределах его основного ареала. Существуют подтверждения того, что диапазирующие копеподы расселяются на большие расстояния в кишечнике рыб (Bartholme et al., 2005) и водоплавающих птиц (Frisch et al., 2007). Копеподы на любых стадиях могут распространяться человеком при использовании лодок, а также ведер, канистр для перевоза воды и даже на орудиях отбора гидробиологических проб (Koksvik et al., 2017; Абрамова, Жулай, 2016). Дополнительным преимуществом E. bidens к колонизации новых местообитаний является редкая для веслоногих раков способность этого вида к однополому размножению самок в отсутствие самцов. Такая особенность биологии приписывается нескольким видам Elaphoidella на основании резкого дефицита самцов в популяциях или того, что до сих пор изучены только самки, однако для E. bidens она достоверно известна и подтверждена экспериментально (Боруцкий, 1952). В популяциях распространенной на северо-востоке европейской части России E. gracilis зарегистрированы особи обоих полов и самцы не редки (Фефилова, 2015).

Анализ морфологии найденной в р. Вычегда E. bidens показал сходство этой особи в вооружении сегментов тела (рис. 3б), числе щетинок на придатке антенны (рис. 2a; 3a), числе придатков на эндоподитах конечностей первой, третьей и четвертой пар (рис. 2б, в; 3 в, г), строении каудальных ветвей и анальной пластинки (рис. 2г; 3д) с рачками из оз. Глубокое в Московской области (Фефилова, 2017), Румынии (Damian-Georgescu, 1970), Новой Зеландии (Lewis, 1972), Борнео и Вьетнама (Apostolov, 2007; Feflova, Alekseev, 2018). 
Экологические и географические морфологические маркеры для гарпактикоид пока не определены (Kochanova et al., 2018). Слабая изученность внутривидовой и популяционной изменчивости этой группы ракообразных не позволяет сделать заключение на основании наибольшего морфологического сходства E. bidens из Вычегодского бассейна и субтропических и тропических областей о происхождении, например, вычегодской находки, так как в формировании этого сходства неизвестной остается роль экологических факторов.

\section{Заключение}

Теплолюбивый вид гарпактикоиды найден к северо-востоку от своего известного ареала, его присутствие в р. Вычегда связано с тепловым загрязнением водоема. Вне зависимости от пути проникновения вида в новое местообитание (со сточными водами из очистных сооружений или из природного водоема, расположенного южнее) его находка свидетельствует о возможном направлении динамики состава сообществ реки при антропогенном изменении условий среды. Обнаружение нового для региона таксона мейобентической копеподы свидетельствует о существующем потенциале расселения этих малоподвижных организмов, их способности к колонизации новых местообитаний при потеплении. Успешному расселению E. bidens могли способствовать зоогеографические и биологические особенности этого всесветно распространенного вида: относительная близость местонахождений наиболее северных нативных популяций, факультативное однополое размножение, широкая биотопическая приуроченность.

\section{Благодарности / Acknowledgements}

Автор благодарен М.А. Батуриной за материал: пробы ракообразных из бентоса р. Вычегда. Исследования выполнены в рамках госзадания отдела экологии животных Института биологии Коми НЦ УрО РАН (№№ АААА-А17-117112850235-2; 0414-2018-0005), Комплексной программы УрО РАН (№№ АААА-А18-118011390005-9; 18-4-4-37), при частичной поддержке гранта РФФИ 18-44-110017 p_a.

The author would like to thank M.A. Baturina for providing the material: samples of crustaceans from benthos of the Vychegda River. The work was performed to implement the State Assignment to the AnimalsEcologyDepartmentoftheInstituteofBiology,KomiSCUrDRAS(AAAA-A17-117112850235-2; 0414-2018-0005), UrD RAS Integrated Program (AAAA-A18-118011390005-9; 18-4-4-37), and, partly, the project for the RFBR grant 18-44-110017 p_a.

\section{Список литературы / References}

Абрамова Е.Н., Жулай И.А. (2016) Появление новых видов зоопланктона в водоемах дельты р. Лены. Труды Зоологического института РАH, 320(4): 473-487 [Abramova E.N., Zhulay I.A. (2016) The occurrence of the new zooplankton species in the Lena River Delta. Proceedings of the Zoological Institute RAS [Trudy Zoologicheskogo instituta RAN], 320(4): 473-487 (in Russian)]

Болотов И.Н., Аксенова О.В., Беспалая Ю.В., Спицын В.М. (2016) Эндемизм фауны пресноводных рыб в геотермальных регионах: обзор молекулярно-биогеографических исследований. Вестник Северного (Арктического) федерального университета. Серия: Естественные науки, 1: 29-50 [Bolotov I.N., Aksenova O.V., Bespalaya Y.V., Spitsyn V.M. (2016) Endemism of freshwater 
fish fauna in the geothermal regions: a review of the molecular and biogeographic studies. Vestnik of Northern (Arctic) Federal University. Series "Natural Sciences" [Vestnik Severnogo (Arkticheskogo) federal'nogo universiteta. Seriya: estestvennye nauki], 1: 29-50 (in Russian)]

Боруцкий Е.В. (1952) Harpacticoida пресных вод. Фауна СССР. T. 3, вып. 4. Ракообразные. М., Л., Изд-во Академии наук СССР, 425 с. [Borutskiy E.V. (1952) Harpacticoida of freshwater. Fauna of USSR. Vol. 3, Issue 4. Crustaceans. Moscow, Leningrad, Academy of Sciences of USSR, 425 p. (in Russian)]

Голдина Л.П., Овчинникова А.И. (1964) Годовые суммы осадков и средние годовые температуры воздуха. Атлас Коми АССР. С.В. Калесник (ред.) М., Главное управление геодезии и картографии Государственного геологического комитета CCCP, с. 28 [Goldina L.P., Ovchinnikova A.I. (1964) Total annual precipation and average annual air temperatures. Atlas of Komi ASSR. S.V. Kalesnik (ed.) Moscow, General Directorate of Geodesy and Cartography of the State Geological Committee of the USSR, p. 28 (in Russian)]

Гусаков В.А. (2007) Мейобентос Рыбинского водохранилища. М., Товарищество научных изданий КМК, 155 с. [Gusakov V.A. (2007) Meiobenthos of the Rybinsk Reservoir. Moscow, KMK Scientific Press, 155 p. (in Russian)]

Тахтеев В.В., Плешанов А.С., Егорова И.Н., Судакова Е.А., Окунева Г.Л., Помазкова Г.И., Ситникова Т.Я., Кравцова Л.С., Рожкова Н.А., Галимзянова А.В. (2010) Основные особенности и формирование водной и наземной биоты термальных и минеральных источников Байкальского региона. Известия Иркутского государственного университета. Серия: Биология. Экология, 3(1): 33-36 [Takhteev V.V., Pleshanov A.S., Egorova I.N., Sudakova E.A., Okuneva G.L., Pomazkova G.I., Sitnikova T.Ya., Kravtsova L.S., Rozhkova N.A., Galimzjanova A.V. (2010) The general peculiarities and genesis of a water and ground biota of thermal and mineral springs in Baikalian region. The Bulletin of Irkutsk State University. Series "Biology. Ecology" [Izvestiya Irkutskogo gosudarstvennogo universiteta. Seriya "Biologiya. Ecologiya"], 3(1): 33-36 (in Russian)]

Фефилова Е.Б. (2015) Фауна европейского Северо-Востока России. Т. ХІІ. Веслоногие раки (Copepoda). М., Товарищество научных изданий КМК, 319 с. [Fefilova E.B. (2015) Fauna of the European North-East of Russia. Vol. 12. Copepods (Copepoda). Moscow, KMK Scientific Press, 319 p. (in Russian)]

Фефилова Е.Б. (2017) Исследования фауны гарпактикоид (Harpacticoida, Copepoda, Crustacea) озера Глубокого. Гидробиологическая станция на Глубоком озере: Труды. Н.М. Коровчинский (ред.) М., Товарищество научных изданий КМК, с. 107-118 [Fefilova E.В. (2017) The faunistic study of harpacticoids (Harpacticoida, Copepoda, Crustacea) of Lake Glubokoe. Proceedings of the Hydrobiological Station "Lake Glubokoe”. N.M. Korovchinsky (ed.) Moscow, KMK Scientific Press, p. 107-118 (in Russian)]

Alekseev V.R., Yusoff F.M., Fefilova E.B. (2016) Continental copepod biodiversity in NorthEastern Borneo, Malaysia. Arthropoda Selecta, 25(2): 183-197

Apostolov A. (2007) Notes sur les harpacticoïdes cavernicoles (Crustacea: Copepoda) de Vietnam du nord. Historia naturalis bulgarica, 18: 65-73

Bartholme S., Samchyshyna L., Santer B., Lampert W. (2005) Subitaneous eggs of freshwater copepods pass through fish guts: survival, hatchability, and potential ecological implications. Limnology and Oceanography, 50(3): 923-929 
Caramujo M.-J., Boavida M.-J. (2009) The practical identification of harpacticoids (Copepoda, Harpacticoida) in inland waters of Central Portugal for applied studies. Crustaceana, 82(4): 385-409

Damian-Georgescu A. (1970) Fauna Republicii Socialiste Romănia. Crustacea. Volumul IV. Fascicula 11. Copepoda. Harpacticoida. Bucuresti, Editura Academiei republicii Socialiste Romania, $249 \mathrm{p}$.

Fefilova E.B., Alekseev V.R. (2018) A new species and new records of harpacticoids (Crustacea: Copepoda: Harpacticoida) from North-Eastern Borneo. Zoosystematica Rossica, 27(2): 205-217

Fiers F., Ghenne V. (2000) Cryptozoic copepods from Belgium: diversity and biogeographic implications. Belgian Journal of Zoology, 130(1): 11-19

Frisch D., Green A.J., Figuerola J. (2007) High dispersal capacity of a broad spectrum of aquatic invertebrates via waterbirds. Aquatic Sciences, 69(4): 568-574

Green J. (1959) Hemoglobin and the habitat of the harpacticoid copepod Elaphoidella gracilis (Sars). Nature, 183: 1834

Kochanova E., Gaviria S. (2018) Intergative taxonomy of the freshwater harpacticoid Attheyella crassa G.O. Sars, 1863 (Crustacea: Copepoda: Canthocamptidae) in the Palearctic region. Invertebrate Zoology, 15(3): 267-276

Kochanova E.S., Fefilova E.B., Sukhikh N.M., Velegzhaninov I.O., Shadrin D.M., Pylina Y.I., Alekseev V.R. (2018) Morphological and molecular-genetic polymorphism of Canthocamptus staphylinus Jurine (Harpacticoida, Copepoda, Crustacea). Inland Water Biology, 11(2): 111-123

Koksvik J.I., Jensen T.C., Kjærstad G. (2017) Heterocope borealis in Norway - a copepod on the move, or on the edge of its natural distribution? Fauna Norvegica, 37: 14-19

Lewis M.H. (1972) Freshwater harpacticoid copepods of New Zealand. 1. Attheyella and Elaphoidella (Canthocamptidae). New Zealand Journal of Marine and Freshwater Research, 6(1-2): 23-47

Neilson M., Fuller P. (2018) USGS Nonindigenous Aquatic Species database. Version 1.102. United States Geological Survey. Occurrence dataset https://doi.org/10.15468/ijccz9 accessed via GBIF.org on 2018-12-03

Reid J.W. (2001) A human challenge: discovering and understanding continental copepod habitats. Hydrobiologia, 453: 201-226

Reid J.W., Williamson C.E. (2010) Copepoda. Ecology and Classification of North American Freshwater Invertebrates. Thorp J.H., Covich A.P. (eds.) London, Academic Press, p. 829-900

Sarkka J. (1995) Profundal meiofauna in two large lakes: Influence of pollution and bathymetric differences. Archiv fur Hydrobiologie, 132(4): 453-493

Wells J.B.J. (2007) An annotated checklist and keys to the species of Copepoda Harpacticoida (Crustacea). Zootaxa, 1568: 1-872

World of Copepods. Copepoda taxon details. Elaphoidella Chappuis, 1929 / World Register of Marine Species (WoRMS) http://www.marinespecies.org/copepoda/aphia.php?p= taxdetails\&id=347106 (Searched on 6 February 2019) 